\title{
FARMÁCIA
}

\section{LEUCEMIA LINFOIDE AGUDA E SEUS PRINCIPAIS CONCEITOS}

\author{
DOI: http://dx.doi.org/10.31072/rcf.v8i2.578 \\ ACUTE LYMPHID LEUKEMIA AND ITS MAIN CONCEPTS \\ Matheus Santos Cavalcante1; Isabelly Sabrina Santana Rosa²; Fernanda Torres ${ }^{3}$.
}

\begin{abstract}
RESUMO: A Leucemia linfoide aguda (LLA) é uma neoplasia maligna heterogênea no sistema hematopoiético, onde ocorre a multiplicação desordenada de células blásticas, ocorrendo o acúmulo de células jovens na medula óssea. O objetivo do presente estudo é de apresentar de forma clara uma revisão de literatura sobre a LLA, seus conceitos, diagnóstico, manifestações clínicas e tratamento. Para a obtenção dos dados, realizou - se uma pesquisa bibliográfica, sendo utilizados materiais já publicados como, artigos científicos, dissertações e teses. Esta patologia acomete em sua grande maioria crianças, chegando a $70 \%$ dos casos. A doença não tem sua etioligia ainda confirmada, dificultando assim a prevenção. Para o diagnóstico são necessários os exames de hemograma, mielograma junto com exames complementares como: morfológico, imunofenotípico, citogenético e molecular. Exames de imunofenotipagem e estudo genético são realizados para saber em que situação se encontra a gravidade do câncer e classificar se o mesmo pertence ao tipo L1, L2 ou L3. Os sintomas mais comuns são: fadiga, letargia, dor óssea, pirexia, palidez, infiltração dos tecidos pelos blastos entre outros. O tratamento depende da situação do quadro clínico em que o paciente se encontra, sua idade, para que assim adote - se o melhor protocolo terapêutico. Os principais protocolos terapêuticos da LLA consistem nas seguintes partes: indução de remissão, tratamento preventivo, intensificação tardia e manutenção de terapia. $E$ também é de grande importância que faça o diagnóstico e a devida escolha do protocolo terapêutico para alcançar o sucesso do tratamento.
\end{abstract}

Descritores (DeCS) ${ }^{4}$ : Leucemia Linfoide Aguda. Sintomas. Etiologia. Diagnóstico. Tratamento.

\begin{abstract}
Acute lymphoid leukemia (ALL) is a heterogeneous malignant neoplasm in the hematopoietic system, where there is a disordered multiplication of blast cells, with the accumulation of young cells in the bone marrow. The objective of the present study is to present a clear literature review on ALL, its concepts, diagnosis, clinical manifestations and treatment. To obtain the data, a bibliographic research was carried out, using already published materials such as scientific articles, dissertations and theses. This pathology affects mostly children,

\footnotetext{
1 Discente do curso de Farmácia da Faculdade de Educação e meio Ambiente - FAEMA. E-mail: matheus102296@gmail.com. ORCID: https://orcid.org/0000-0002-1079-740X;

2 Discente do curso de Farmácia da Faculdade de Educação e meio Ambiente - FAEMA. E-mail: isabelly_sabrina@hotmail.com. ORCID: https://orcid.org/0000-0003-3498-9227;

${ }^{3}$ Biomédica, pós graduada em Hematologia, Docente do Curso de Farmácia na Faculdade de Educação e Meio Ambiente - FAEMA. E-mail: fernandat_torres@hotmail.com. ORCID: https://orcid.org/0000-0001-7203-9033.

4 Vide http://decs.bvs.br.
} 
reaching $70 \%$ of the cases. The disease does not have its etiology still confirmed, making prevention difficult. For the diagnosis, hemogram, myelogram, and complementary exams such as morphological, immunophenotypic, cytogenetic and molecular, are required. Immunophenotyping and genetic studies are performed to determine the severity of the cancer and to classify it as L1, L2 or L3. The most common symptoms are: fatigue, lethargy, bone pain, pyrexia, paleness, infiltration of tissues by blasts, among others. The treatment depends on the clinical situation in which the patient is, his age, so that the best therapeutic protocol is adopted. The main therapeutic protocols of ALL consist of the following parts: induction of remission, preventive treatment, delayed intensification and maintenance of therapy. And it is also of great importance to make the diagnosis and the proper choice of the therapeutic protocol to achieve the success of the treatment.

Descriptors: Acute Lymphoid Leukemia. Symptoms. Etiology. Diagnosis. Treatment.

\section{INTRODUÇÃO}

A leucemia linfoide aguda (LLA) é um câncer, que apresenta uma proliferação desordenada de glóbulos brancos (linfoides) imaturos, ocupando um grande espaço na medula óssea onde ocorre sua produção, impedindo assim a produção das plaquetas e glóbulos vermelhos ${ }^{(1,2)}$.

A doença ocorre normalmente em crianças dos dois aos cinco anos de idade sendo mais frequentes em meninos e em pessoas de cor branca, seu quadro clínico é bastante diferenciado se transformando conforme o desenvolvimento da doença a qual irá comprometendo aos poucos a medula. Exaustão, desânimo, perca de massa são alguns dos sintomas mais comuns, a pirexia está presente em muitos casos. Outros sintomas também são relatados em alguns casos como artrite, mucosite oral entre outros ${ }^{(3)}$.

A falta de nutrientes essenciais para o organismo faz com que haja a falta de apetite, que consequentemente irá reduzir a resistência do sistema imunológico e a infecções, comprometendo 0 desenvolvimento da criança, deixando-a exposta a doenças como a anemia (4).

Para que se tenha o diagnóstico prévio da doença, é realizado o hemograma (exame de sangue) ao mesmo tempo é a realizado a distensão sanguínea, para fins de avaliar o índice de leucometria no sangue, podendo estar aumentado, abaixo ou igual ao valor de referência. Para que haja o diagnóstico definitivo é realizado o mielograma que fará a análise da amostra de medula óssea, normalmente retirado do osso esterno ou do ilíaco e deverá ser constatado um número maior ou equivalente a $20 \%$ de células imaturas ${ }^{(5)}$. É através do exame de imunofenotipagem, que é possível distinguir imunologicamente e classificar a LLA, sendo classificado em linhagem B ou T, de acordo com os traços imunofenotípicos dos linfoblastos. ${ }^{(1)}$. 
O tratamento é fundamentado em quimioterapia, tendo atenção à condição clínica, imunológica, citogenéticas do paciente e se há ou não algum comprometimento e/ou abrangência de outros órgãos, para escolha do método mais efetivo ${ }^{(6)}$. A quimioterapia é dívida em três etapas: indução, consolidação e manutenção. No meio de tantas drogas utilizadas, uma das principais é o metotrexato (MTX), que atua inativando a disseminação das células malignas, administrado em alta concentração na fase de consolidação no processo quimioterápico. O mesmo possui efeitos adversos, afetando os revestimentos mucosos do organismo ${ }^{(7)}$. A presença de sintomas negativos ou recaída da patologia deve ser abordada em tratamentos mais agressivos, no caso o transplante de medula óssea ${ }^{(8)}$.

Portanto, o presente estudo tem como ponto central apresentar uma revisão de literatura, sobre o câncer leucêmico, voltado para a LLA, tendo assim como objetivos específicos apresentar sua forma de manifestação, diagnóstico, tratamento associado, com intuito de esclarecimento e contribuição dos estudos sobre o mesmo.

\section{METODOLOGIA}

O presente artigo trata - se de uma revisão da literatura acerca do tema Leucemia, mais precisamente sobre a LLA.
A coleta de dados foi realizada através de pesquisas bibliográficas em plataformas científicas, tais como: Scielo, Google Acadêmico, Biblioteca Virtual em Saúde BVS, Lilacs e revistas científicas.

Dentre os materiais coletados foram utilizados artigos de revistas, dissertações, teses e monografias. Para a seleção dos materiais a serem utilizados não foi determinado um lapso temporal específico, mas os que foram selecionados compreendem o período de 2002 a 2017. Possuindo trabalhos em língua inglesa, portuguesa e espanhola. E para que se tivesse uma abordagem atual do tema possui onze trabalhos dentro dos últimos cinco anos (2012-2017).

Os seguintes termos foram utilizados para realizar os levantamentos dos dados: Leucemia Linfoide Aguda, protocolos terapêuticos para 0 tratamento de leucemias, manifestações clínicas da LLA. Sendo os critérios de exclusão: os materiais com temáticas de estudo divergente da proposta e que não pertencesse a uma plataforma de dados confiáveis.

\section{REVISÃO DE LITERATURA}

\subsection{Leucemia Linfoide Aguda}

A LLA se caracteriza pela propagação danosa das células linfoides na medula óssea, ocasionando assim acúmulo das células jovens, caracterizadas como 
blastos ${ }^{(9)}$. Devido as células leucêmicas serem heterogêneas, apresentam vasta diversidade de dados clínicos e biológicos (10). A mesma compromete a produção de todas as células sanguíneas. A LLA avança desde os linfloblastos primordiais, que se encontram em inúmeros pontos de evolução. Para realizar a classificação o método primordial é a imunofenotipagem (11). Através da citologia, imunohistoquímica e citogenética é possível caracterizar como leucemia linfoide aguda (LLA), e leucemia mieloide aguda (LMA) (13).

De forma que se aglomeram na medula óssea as células leucêmicas extinguem a ampliação das células geradoras hematopoiéticas normais, observando os sintomas clínicos normalmente relatados em casos de leucemias agudas, sendo eles: anemia, infecções e hemorragias que são provenientes da falta de hemácias, leucócitos operacionais e plaquetas ${ }^{(9)}$. $O$ aumento dos blastos na medula extingue 0 desenvolvimento e a boa ação das células precursoras dos grupos eritrócitos, granulócitos e megacariócitos ${ }^{(5)}$. Dentre as leucemias agudas a LLA, é a mais frequente em crianças de 0 a 14 anos, cerca de $80 \%{ }^{(10)}$. Incidem neste mesmo grupo citado anteriormente em uma frequência de 1 em 25.000 e sua probabilidade de ser diagnosticada nos 10 primeiros anos é de 1 em 2.880. A LLA é mais frequente em crianças caucasianas do que negras, e do sexo masculino do que feminino ${ }^{(9)}$.

A etiologia ainda não foi devidamente comprovada, mas estudos baseiam - se como prováveis causas: efeitos de irradiação em consequência do aumento de casos no Japão após 0 ataque de Hiroshima e Nagasaki, exposição a drogas antineoplásicas, fatores genéticos associados, imunológicos e exposição a alguns vírus ${ }^{(11)}$. Como nos outros diversos tipos de câncer partem de mutações gênicas do DNA de células somáticas. Outros fatores considerados são os ambientais tais eles como: exposição a agentes químicos, fármacos, exposição à radiação ionizante, radioterapia e quimioterapia ${ }^{(9)}$. O tabagismo passivo de crianças com pais fumantes pode vir a acarretar neoplasias.

$\mathrm{Na}$ LLA em pacientes adultos, possui fatores prognósticos de elevado risco, como o imunofenótipo $B$, modificações cromossômicas e, a presença do cromossomo $\mathrm{Ph}+{ }^{(8,10)}$. Assim como na grande maioria de doenças neoplásicas, o desenrolamento de eventos que resultam em alterações malignas parte de uma célula multifatorial. Estes mesmos eventos sucedem durante a evolução da linhagem 
linfoide. Os precursores linfoides têm uma alta taxa de multiplicação e ajuste genéticos. Atributos que facilitam 0 surgimento de mutações espontâneas e outras anomalias citogenéticas ${ }^{(16)}$.

As leucemias são consideradas diferentes dos demais tipos de câncer, devido seu desenvolvimento, já que para sua disseminação, não são necessários mecanismos de angiogênese, ruptura estrutural, e de produção de metástase, que são frequentes nos demais (9). Nos anos de 2005 a 2009 um estudo realizado relata que os índices de sobrevivência da LLA foram acima de $90 \%$, nos seguintes países: Áustria, Bélgica, Canadá, Alemanha e Noruega. Em outros países como Indonésia e Mongólia esse índice se encontra abaixo de $50 \%$. Dentro do período de 1995 a 2009, a sobrevida teve variação de $72 \%$ a $66 \%$ no Brasil ${ }^{(14)}$. Outro grande fator no aumento da sobrevida está relacionado com a otimização nos protocolos terapêuticos, e que marca um grande avanço da moderna hematologia pediátrica ${ }^{(15)}$.

\subsection{LLA - Manifestação clínica e diagnóstico}

A LLA apresenta manifestações clínicas consequentes da proliferação dos blastos, que substituem as células normais, impedindo assim que desencadeiem suas funções. Os sintomas são heterogêneos, alterando

se

conforme

comprometimento medular e extra medular, os mais relatados são: fadiga, letargia, dor óssea (difusa ou localizada) com tendência de se tornar artralgia e/ou artrite, diferentes graus de anemia, perda de peso, neutropenia, trombocitopenia, infiltração dos tecidos pelos blastos, palidez, pirexia, sangramento $(2,3,5,7,22)$.

$\mathrm{Em}$ casos mais graves pode apresentar aumento dos gânglios, inflamação dos testículos, vômitos, dor de cabeça, acometimento ocular, priapismo e síndromes compressivas medulares. A LLA manifesta sintomas distintos, que tem muita semelhança aos sintomas de outras patologias, algumas delas são as seguintes: artrite reumatoide juvenil, febre reumática, aplasia medular, entre outras ${ }^{(3)}$.

Manifestações orais estão presentes em grande parte dos casos, sendo classificadas em três grupos: lesões primárias, lesões secundárias, lesões terciárias. Nas manifestações primárias, os blastos podem infiltrar - se no tecido gengival e no osso alveolar. Já nas secundárias apresentam lesões associadas com anemia, úlcera neutropênicas entre outros. Os sintomas terciários ocorrem devido ao tratamento neoplásico ${ }^{(23,24)}$.

A diagnose da LLA é fundamentada essencialmente através dos exames morfológicos e citoquímicos das células 
neoplásicas. (18) $\mathrm{Na}$ investigação laboratorial da doença, possui quatro meios de destaques: morfológico, imunofenotípico, citogenético e molecular, contudo são considerados exames completamentares.

O hemograma pode evidenciar a presença de anemias normocítica, normocrômica e trombocitopenia. $\mathrm{O}$ índice de leucometria na grande maioria dos casos está elevado, superior a $100.000 / \mathrm{mm}^{3}$. Porém $1 / 4$ dos relatos, paciente com LLA apresentam 0 valor abaixo de $4.000 / \mathrm{mm}^{3}$, raramente são encontrados blastos nestes casos. Em casos de leucocitose os blastos podem ser numerosos e constituir uma grande parte da contagem ${ }^{(1,18,21)}$.

O mielograma consiste em fazer a análise do conteúdo da medula óssea, fazendo a punção aspirada, geralmente no osso esterno ou ilíaco. Na leitura do exame avalia - se a quantidade de blastos presentes no tecido, sendo diagnosticada leucemia se estiver presente mais de $25 \%$ da concentração total ${ }^{(1,18,21)}$.

Como nos demais tipos de patologias malignas, classificamos a LLA em conformidade com os atributos das células. Atualmente a classificação morfológica em vigor é comumente utilizada, foi desenvolvida por um grupo denominado Franco-Americano-Britânico (FAB). De acordo com a $F A B$ os blastos possuem baixa quantidade de citoplasma com basofilia variada. Os blastos são classificados em três tipos distintos (18,19):

L1: células pequenas, com morfologia regular, homogêneos, sem nucléolos, relação núcleo-citoplasma alta; Conforme Figura 1.

Figura 1 - Células da Leucemia linfoide aguda classificados como L1.

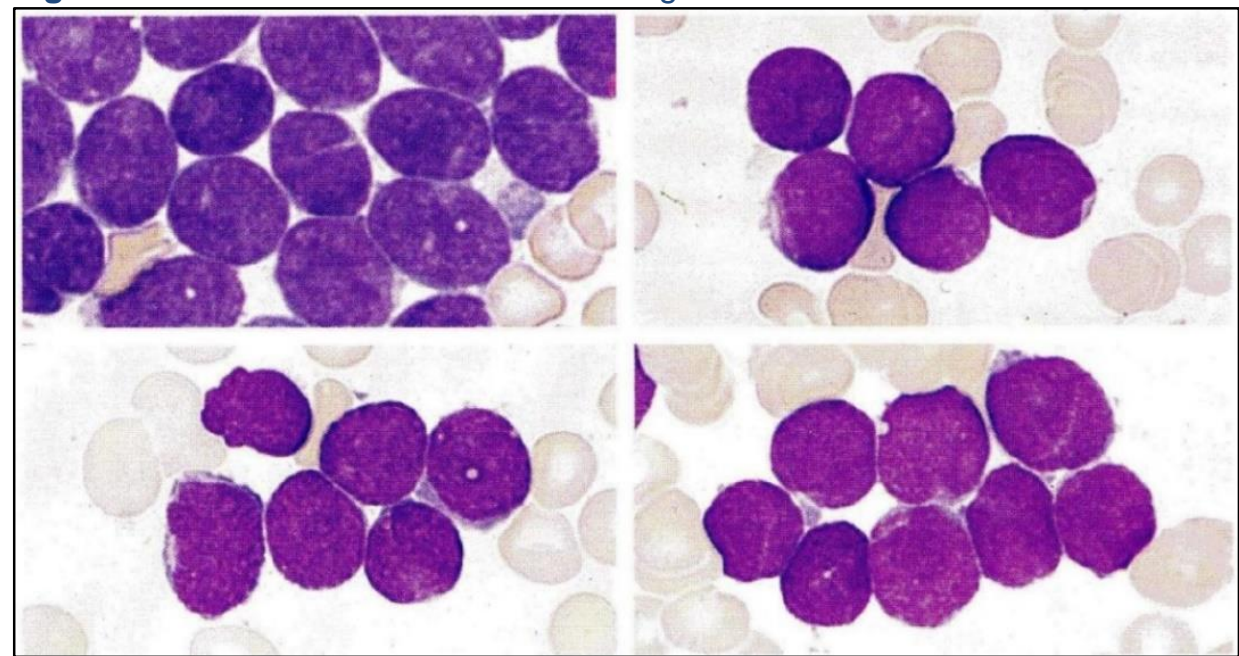

Fonte: Fadel (2010). 
L2: células de tamanhos variáveis, irregularidade no contorno. Conforme heterogêneos, possuem nucléolos grandes Figura 2. e visíveis, podendo apresentar

Figura 2 - Células da Leucemia linfoide aguda classificados como L2.

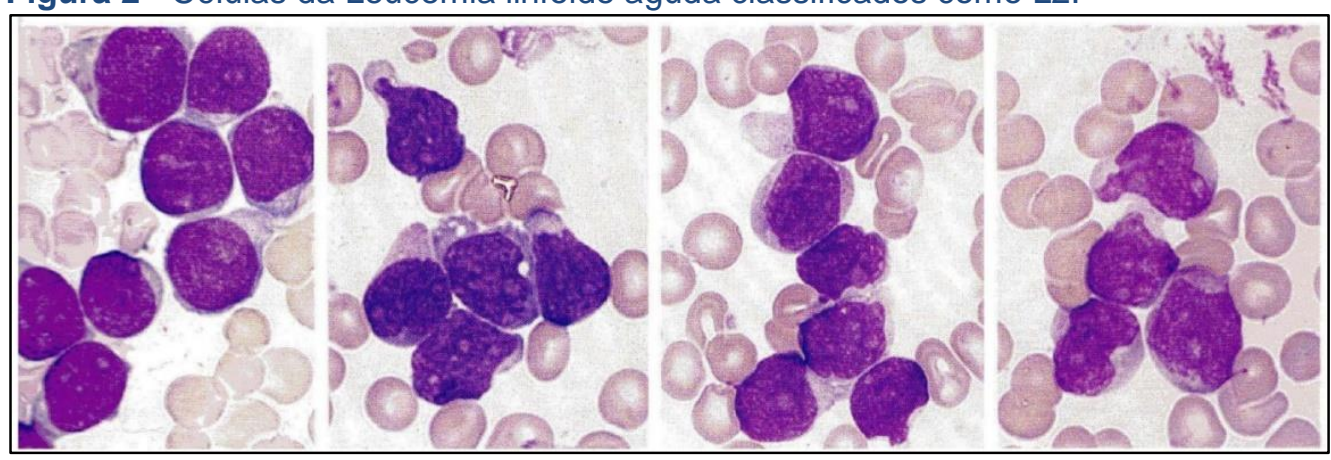

Fonte: Fadel (2010)

L3: células grandes, basofilia citoplasmática, apresentam imunofenotipo $B$, é considerada sendo uma forma mais agravante da patologia, apresenta forma leucêmica do linfócito de Burkitt. Conforme Figura 3.

Figura 3 - Células da Leucemia linfoide aguda classificados como L3

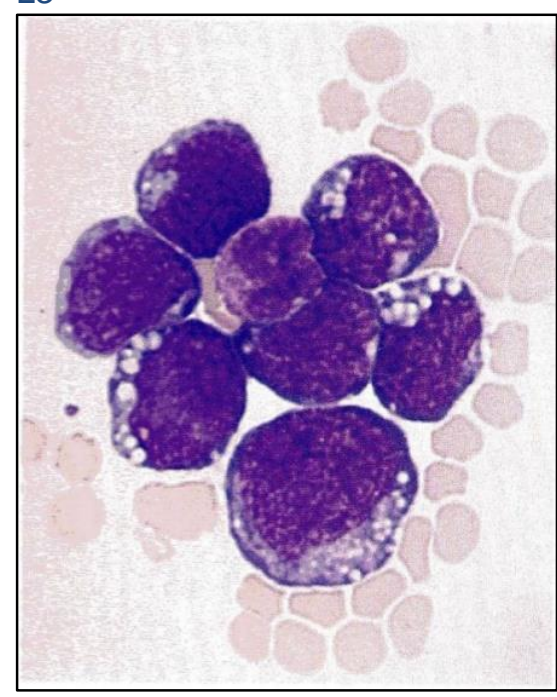

A classificação da imunofenotipagem, comumente usada foi estabelecida pelo European Group for Immunophenotyping Leukemias (EGIL), que é baseado na representação imunofenótipica das células, que estão em concordância com a morfologia do caso, possibilitando assim a distinção em subtipos imunológicos, após a
Fonte: Fadel (2010).

verificação, podemos classificar a linhagem celular (B ou T) ${ }^{(20)}$.

A leucemia da linhagem $B$ está separada em quatro subtipos, sendo que cada um deles está ligada com o estágio de maturação dos progenitores, são eles: pró$\mathrm{B}$, comum, pré-B e B-maduro. As células do tipo pró-B expõem: HLA-DR, Terminal 
Desoxinucleotidil Transferase (TdT), CD34, CD19 e CD22. A do tipo comum também denominada Calla, expressa CD10, que tem grande influência positiva no prognostico, CD22, CD19 ou CD20. A LLA do tipo pré-B apresenta cadeia $\mu$ citoplasmática, com a inclusão de CD19, CD20 e CD10. A tipo B-maduro caracteriza - se pela expressão de cadeias de imunoglobina na membrana em sua superfície ${ }^{(20)}$.

A linhagem $\mathrm{T}$, apesar de ter menos frequência, é separada em subgrupos, na conformidade com os diferentes estágios de maturação das células $T$ no timo, são elas pré-T, T-intermediário e LLA Tmadura. Dentro da LLA pré-T, as células liberam CD3, e também CD7,CD2, CD5 e TdT. Na T intermediária, as células passam a apresentar CD3c, CD2, CD1, e podem reapresentar CD4 e CD8. A T-madura expressa os mesmos marcadores que a Pré-T ${ }^{(20)}$.

A imunofenotipagem, feita com a técnica de citometria de fluxo (CMF), é eficaz no reconhecimento, especificação, prognosticação, determinação da extensão da doença, monitorização, e também na definição fenotípica das leucemias. Ainda assim, as análises citogenéticas e moleculares concedem uma elucidação mais fundamental no reconhecimento das leucemias. Exames citogenéticos e moleculares proporcionam a constatação de modificações cromossômicas e genéticas das células afetadas, ligando-as com o reconhecimento, a identificação, a tipificação de diversas etapas, a verificação da intermissão e parecer destas patologias (17).

As reações citoquímicas ajudam na identificação entre LLA e LMA. Exames com o uso da coloração mieloperoxidase e Sudan Black, são vantajosos para confirmação da LMA, devido à mesma ser negativo para blastos leucêmicos. A reação de fosfatase alcalina é muito útil para diagnóstico da LLA tipo T. No exame periódica ácida de Schiff (PAS), blastos da LLA são normalmente positivos e estão relacionados com LLA tipo $B$ e quando apresentam resultado negativo é costumeiro apresentar na linhagem $T^{(1,21)}$.

As anomalias cromossômicas, no momento em que coligado ao painel de imunofenotipagem, estabelece 0 fator de altíssima importância para a categorização das leucemias, e devidamente acompanhado de outros fatores clínicos e laboratoriais, permitem a classifação dos enfermos de acordo com o grau de severidade da patologia, sendo de extrema importância para estabelecer uma terapêutica eficaz (1). Dentre as anormalidades ocorridas, as translocações ocorrem em $40 \%$ dos casos, devido a 
rearranjos gênicos ou alterações na regulação dos oncogenes. As comumente encontrados estão nos grupos com pseudiploida e hipodiploida, a $\mathrm{t}(8 ; 14)$, $\mathrm{t}(4 ; 11)$ e $\mathrm{t}(4 ; 19)$, em crianças as com maior índice frequência são $t(8 ; 14), t(9 ; 22)$, $\mathrm{t}(12 ; 21), \mathrm{t}(4 ; 11)$ e $\mathrm{t}(1 ; 19)$ (22).

\subsection{LLA - Tratamento.}

Para dar início ao tratamento da LLA, precisa - se ter o diagnóstico correto, confirmado pelos exames de imunofenotipagem, citoquímica, citogenética e juntamente levando em consideração a idade, quadro clinico apresentado, para que assim possa ser escolhido o melhor protocolo terapêutico $(2,25)$.

Várias combinações de drogas são utilizadas para o controle da proliferação da doença, a escolha do correto protocolo de tratamento é de extrema importância para que o paciente tenha boas chances de cura (26).

O Grupo Brasileiro Cooperativo para tratamento de Leucemia na Infância (GBTLI) nos anos de 1980 começaram os estudos para desenvolver protocolos terapêuticos. No ano de 1999 foi dividida em dois grupos sendo eles: Grupo de baixos riscos e Grupo de altos riscos. Foram desenvolvidos protocolos como o GBTLI-80 nos anos de 1980 a 1982, os próximos protocolos foram os GBTLI-82,
GBTLI-85, GBTLI-93 e GBTLI-99, que teve sua última atualização em dezembro de $2001^{(26,27)}$.

Os principais protocolos terapêuticos da LLA consistem nas seguintes partes: indução de remissão, tratamento preventivo, intensificação tardia (há casos de ocorrer divisões em fases de reindução e consolidação) e manutenção de terapia. Estas mesmas fases do tratamento são especificas para cada grupo de risco (27).

A racionalização dos grupos é realizada de acordo com a idade do paciente, leucometria inicial, se possui ou não translocações genética e contagem de leucócitos no sangue periférico no $8^{\circ}$ dia após o início da quimioterapia ${ }^{(25)}$. Sendo eles assim divididos: Grupo de baixo risco: idade $\geq$ a 1 ano e $<9$ anos; leucometria $<50.000 / \mathrm{mm}^{3}$ na fase de diagnóstico, e $<5.000 / \mathrm{mm}^{3}$ no $7^{\circ}$ dia de tratamento; ausência de blastos no sangue periférico, comprometimento medular no $14^{\circ}$ dia deve estar baixo, medula com baixo índice de leucócitos no 28 dia na fase da indução. Grupo de alto risco: idade $<1$ ano $\mathrm{e} \geq 9$ anos; leucometria maior que $50.000 / \mathrm{mm}^{3}$ na fase de diagnóstico, baixa resposta terapêutica ao tratamento, contagem de leucócitos $\geq$ a 5.000 no $7^{\circ} \mathrm{dia}$, presença de blastos no sangue periférico ou comprometimento medular extenso no $14^{\circ}$ dia ${ }^{(15)}$. 
A primeira parte do tratamento é a terapia de indução, que possui como principal objetivo impulsionar a restauração da produção normal das células sanguínea. Os valores de hemograma devem estar dentro dos padrões, o sistema hematopoiético restaurado e em funcionamento. Também deve ocorrer nessa fase o tratamento ou prevenção da doença no sistema nervoso central, que consiste no processo de quimioterapia intratecal $(25,26,27)$.

Após a etapa de remissão da doença, temos o processo de consolidação, um período de tratamento intenso, com 0 objetivo de prevenir o surgimento de células resistente aos fármacos. Esse processo associa quimioterapia sistêmica com a intratecal, para consolidar a $1^{\circ}$ fase de indução ${ }^{(15,25)}$.
A fase de manutenção se dá início após completar de seis a doze meses de tratamento intensivo, que fará o uso de baixas concentrações de drogas como 6Mercaptopurina e MTX, que agem no aumento do tempo da indução. Esta fase do tratamento pode chegar a um período de até dois anos, e tem como seu principal objetivo prevenir o retorno da doença ${ }^{(15,25)}$.

Durante o período de tratamento, geralmente ocorre o surgimento de efeitos adversos como vômitos, náuseas, diarreia, mucosite gastrointestinal, eritema, erupções, maculo papilar, dermatite entre outras patologias (25).

Existem no mundo outros protocolos de tratamento da LLA, como o BFM desenvolvido pelo grupo Berlim-FrankfurtMunique na Alemanha, que possui características semelhantes ao protocolo brasileiro GBTLI.

Quadro 1 - Medicamentos e doses especificadas no protocolo GBTLI-99 de pacientes com baixos índices de recaída.

\begin{tabular}{|c|c|}
\hline ETAPA (DURAÇÃO) & MEDICAMENTO (DOSES) \\
\hline $\begin{array}{l}\text { Indução da remissão } \\
\text { semanas) }\end{array}$ & $\begin{array}{l}\text { Prednisona }(40 \mathrm{mg} / \mathrm{m} 2 / \mathrm{dia}) \\
\text { Vincristina }(1,5 \mathrm{mg} / \mathrm{m} 2 / \mathrm{sem}) \\
\text { L-asparaginase }(5000 \mathrm{UI} / \mathrm{m} 2 / \text { dia }) \\
\text { Daunorrubicina }(25 \mathrm{mg} / \mathrm{m} 2 / \text { semana) } \\
\text { MADIT }\end{array}$ \\
\hline $\begin{array}{l}\text { Consolidação da remissão (2 } \\
\text { semanas) }\end{array}$ & $\begin{array}{l}\text { Ciclofosfamida (1g/m2/dose) } \\
\text { Citarabina ( } 75 \mathrm{mg} / \mathrm{m} 2 / \mathrm{dose}) \\
\text { 6-Mercaptopurina (50 mg/m2/dia) } \\
\text { MADIT }\end{array}$ \\
\hline Intensificação (8 semanas) & $\begin{array}{l}\text { Metotrexato }(2 \mathrm{~g} / \mathrm{m} 2 / \text { dose }) \\
6 \text {-Mercaptopurina }(50 \mathrm{mg} / \mathrm{m} 2 / \mathrm{dia}) \\
\text { MADIT }\end{array}$ \\
\hline Consolidação tardia (8 semanas) & $\begin{array}{l}\text { Dexametasona (6 mg/m2/dia) } \\
\text { Vincristina (1,5mg/m2/dose) } \\
\text { Doxorrubicina (30 mg/m2/dose) } \\
\text { L-asparaginase }(5000 \mathrm{Ul} / \mathrm{m} 2 / \text { dose }) \\
\text { Ciclofosfamida (1 } \mathrm{g} / \mathrm{m} 2 / \text { dose }) \\
\text { Tioguanina ( } 60 \mathrm{mg} / \mathrm{m} 2 / \text { dia })\end{array}$ \\
\hline
\end{tabular}




\begin{tabular}{|c|c|c|}
\hline & MADIT & \\
\hline $\begin{array}{l}\text { Manutenção ( } 1 \text { ano e } 6 \text { meses - } \\
\text { destinados a cada grupo } \\
\text { aleatoriamente) }\end{array}$ & 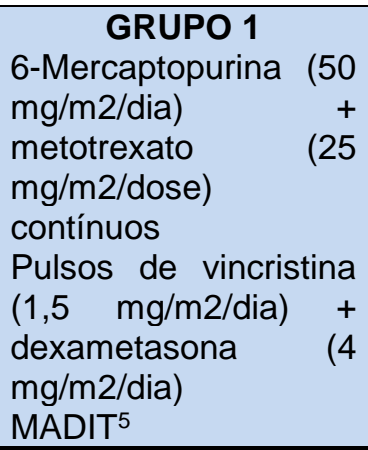 & \begin{tabular}{l}
\multicolumn{1}{c}{ GRUPO 2} \\
6-Mercaptopurina \\
$\mathrm{mg} / \mathrm{m} 2 /$ dia) \\
metotrexato $(200 \mathrm{mg} / \mathrm{m} 2)$ \\
intermitentes. \\
Pulsos de vincristina $(1,5$ \\
$\mathrm{mg} / \mathrm{m} 2 /$ dia $)$ \\
dexametasona \\
$\mathrm{mg} / \mathrm{m} 2 /$ dia $)$ \\
MADIT
\end{tabular} \\
\hline
\end{tabular}

Fonte: Cazé (2010).

\section{CONSIDERAÇÕES FINAIS}

O presente estudo relata sobre a LLA, sendo o tipo de câncer mais frequente em crianças e adolescentes menores de quinze anos, ocorrem casos em adultos, porém são menos frequentes. A etiologia da LLA ainda não foi descoberta somente a suspeitas sobre possíveis causas, isso dificulta com que possamos a evitar a proliferação e a prevenção da mesma. Suas manifestações clínicas iniciais são facilmente confundidas com outras patologias mais simples. Com o desenvolvimento e aperfeiçoamento dos protocolos terapêuticos 0 índice de prognostico da doença vem aumentando, devido ao correto diagnóstico no início da patologia, em alguns países europeus como Alemanha e Noruega, as chances de remissão completa da doença supera $90 \%$. Sendo assim é de suma importância o conhecimento por parte de profissionais da saúde sobre os sintomas, diagnósticos e tratamento da LLA.

\section{REFERÊNCIAS}

1. Farias MG, Castro SM. Diagnóstico laboratonal das leucemias linfoides agudas. 2004. [citado em 09 de abril de 2017]. Disponível em: http://www.scielo.br/pdf/jbpml/v40n2/a08v4 On2

2. Ikeuti PS, Borim LNB, Luporini RL. Dor óssea e sua relação na apresentação inicial da leucemia linfoide aguda. Revista Brasileira de Hematologia e Hemoterapia, v. 28 , n. 1, p. 45-48, 2006 [citado em 10 de abril de 2017]. Disponível em: http://www.scielo.br/pdf/rbhh/v28n1/v28n1a 11

3. Barbosa CMPL, Nakamura C, Terreri MT, Lee MLM, Petrilli AS, Hilário MOE. Musculoskeletal manifestations as the onset of acute leukemias in childhood. Jornal de pediatria, v. 78, n. 6, p. 481-484, 2002 [citado em 10 de abril de 2017]. Disponível em: http://www.scielo.br/pdf/jped/v78n6/780648 1.pdf

4. Pavanelli MF, Gomes JR. Perfil das alterações hematológicas em crianças

${ }^{5}$ MADIT = combinação de metotrexato, citarabina e dexametasona administrada intratecalmente. 
residentes na região de Campo Mourão PR. Revista Iniciare, v. 1, n. 1, 2016 [citado em 09 de abril de 2017]. Disponível em: http://revista.grupointegrado.br/revista/inde x.php/iniciare/article/view/2327

5. Silva KR, Gomes DLR. Profilaxia com Sulfametoxazol/Trimetoprim em pacientes pediátricos com Leucemia Linfoide Aguda. Base de Trabalhos de Conclusão de CursoIFRJ-Campus Realengo, v. 1, n. 1, 2014 [citado em 09 de abril de 2017]. Disponível em:

http://revistascientificas.ifrj.edu.br:8080/revi sta/index.php/saudeeconsciencia/article/vi ew/353/244

6. Rocha BC. Leucemia linfoide aguda: relato de um caso e revisão de literatura. Comissão de Residência Médica do Hospital do Servidor Público Municipal. São Paulo (SP), 2012. [citado em 10 de abril de 2017]. Disponível em: http://sms.sp.bvs.br/lildbi/docsonline/get.ph $p$ ? id $=2651$

7. Santos GDM. Estudo da severidade da mucosite oral em crianças com leucemia linfoblástica aguda em hospital de referência em Natal-RN. 2015. [Monografia] - Departamento de Odontologia, Universidade Federal do Rio Grande do Norte, Natal, 2015 [citado em 09 de abril de 2017]. Disponível em: https://monografias.ufrn.br/jspui/handle/12 3456789/2993

8. Hamerschlak N. Leucemia: fatores prognósticos e genética. J Pediatr (Rio de Janeiro), v. 84, n. 4, p. S52-S7, 2008 [ citado em 10 de abril de 2017]. Disponível em: http://www.jped.com.br/conteudo/0884-S52/port.asp

9. Gil EA. Investigação das alterações citogenéticas em pacientes pediátricos com leucemia linfoide aguda do rio grande do norte. 2011 [citado em 07 de maio de 2015]. [Dissertação de Mestrado]. Universidade Federal do Rio Grande do Norte. Disponível em: http://www.repositorio.ufrn.br:8080/jspui/ha ndle/123456789/13471

10. Zanichelli MA, Colturato VR, Sobrinhi J. Indicações em transplante de célulastronco hematopoéticas em pacientes adultos com leucemia linfoide aguda. Rev Bras Hematol Hemoter, v. 32, n. 1, p. 54-60, 2010 [citado em 07 de maio de 2017]. Disponível em: http://www.scielo.br/pdf/rbhh/v32s1/aop300 10

11. Elman I, Silva MEMP. Crianças portadoras de leucemia linfoide aguda: análise dos limiares de detecção dos gostos básicos. Revista Brasileira de Cancerologia, v. 53, n. 3, p. 297-303, 2007 [citado em 07 de maio de 2017]. Disponível em:

http://www.inca.gov.br/rbc/n_53/v03/pdf/art igo3.pdf

12. Woo JS, Alberti MO, Tirado CA. Childhood B-Acute Lymphoblastic Leukemia: A Genetic Update. Experimental Hematology \& Oncology 3 (2014): 16. PMC. Web [citado em 08 de maio de 2017]. Disponível em: https://ehoonline.biomedcentral.com/article s/10.1186/2162-3619-3-16

13. Macêdo TMF, Campos TF, Mendes REF, França DC, Chaves GSS, Mendonça KMPP . Função pulmonar de crianças com leucemia aguda na fase de manutenção da quimioterapia. Revista Paulista de Pediatria, v. 32, n. 4, p. 320-325, 2014 [ citado em 08 de maio de 2017]. Disponível em:

http://www.sciencedirect.com/science/articl e/pii/S0103058214000070

14. Ministério da Saúde (BR), Instituto Nacional de Câncer José Alencar Gomes da Silva (INCA). Incidência, mortalidade e morbidade hospitalar por câncer em crianças, adolescentes e adultos jovens no Brasil: Informações dos registros de câncer e do sistema de mortalidade. 1. ed. Rio de Janeiro: Nstituto Nacional de Câncer José Alencar Gomes da Silva, 2016. 412 p. v. 1 
[citado em 09 de maio de 2017]. Disponível em:

http://www1.inca.gov.br/wcm/incidencia/20 17/pdf/versao-completa.pdf

15. Cazé MO, Bueno D, Santos MEF. Estudo referencial de um protocolo quimioterápico para leucemia linfocítica aguda infantil. Revista HCPA. Porto Alegre. Vol. 30, n. 1 (2010), p. 5-12, 2010 [citado em 16 de maio de 2017]. Disponível em: http://hdl.handle.net/10183/23680

16. Atienza AL. Leucemias. Leucemia linfoblástica aguda. Pediatria Integral, v. 16, n. 6, p. 453-462, 2012 [citado em 17 de maio de 2017]. Disponível em: http://www.pediatriaintegral.es/wpcontent/uploads/2016/09/Pediatria-IntegralXX-06_WEB.pdf\#page=33.

17. Quixabeira VBL, Saddi VA. A importância da imunofenotipagem e da citogenética no diagnóstico das leucemias: uma revisão da literatura. RBAC, v. 40, n. 3 , p. 199-202, 2008 [acesso em 16 de maio de 2017]. Disponível em: https://www.researchgate.net/profile/Vera Saddi/publication/240617946_A_importanc ia_da_imunofenotipagem_e_da_citogeneti ca_no_diagnóstico_das_leucemias_uma_r evisao_da_literatura_The_importance_of_i mmunophenotyping_and_cytogenetics_in the_diagnosis_of_leukemia_a_literatur/link s/547e43b50cf2c1e3d2dc1d13.pdf

18. Fadel AP. Investigação Laboratorial de LLA. AC\&T Científica, v. 1, 2010 [citado em 20 de maio de 2017]. Disponível em: http://www.ciencianews.com.br/arquivos/A CET/IMAGENS/revista_virtual/hematologia /artapfadel.pdf

19. Ruas AM, Pitol $H$, Nardin JM. Elaboração de uma biblioteca de lâminas de pacientes pediátricos com leucemia linfoblástica aguda (LLA). Saúde, v. 1, n. 9, 2014 [citado em 19 de maio de 2017]. Disponível em: http://revistas.unibrasil.com.br/cadernossa ude/index.php/saude/article/download/144/ 143
20. Dutra, LLA. Avaliação dos genes AURKA e AURKB em pacientes pediátricos portadores de leucemia linfoide aguda. 2015 [citado em 19 de maio de 2017]. [Tese de Doutorado]. Disponível em: http://repositorio.ufc.br/handle/riufc/14019

21. Almeida TJB. Avanços e perspectivas para o diagnóstico da Leucemia Linfoide Aguda. Candombá, p. 40-55, 2009 [citado em 20 de maio de 2017]. Disponível em: http://revistas.unijorge.edu.br/candomba/2 009-

v5n1/pdfs/TeresaJoelma2009v5n1.pdf.

22. Ribeiro ECP, Perlamagna SAF. Leucemias na clínica pediátrica. Pediatria Moderna, [S.I.], v. 51, n. 9, p. 337-342, set. 2015 [citado em: 21 de maio de 2017]. Disponível em: http://www.moreiraj.com.br/revistas.asp?f ase $=r 003 \& i d \_m a t e r i a=6179$

23. Silva LCP, Carneiro FM, Cruz RA. Manifestações bucais das leucemias agudas na infância. Arquivo Brasileiro de Odontologia, v. 4, n. 1, p. 40-54, 2010 [citado em 21 de maio de 2017]. Disponível em:

http://200.229.32.55/index.php/Arquivobras ileirodontologia/article/download/1254/130 7

24. Trindade AKF, Biase RCCG, Filho GG, Pereira BC, Souza EMD, Queiroga AS. Manifestações orais em pacientes pediátricos leucêmicos. Arquivos em Odontologia, v. 45, n. 1, 2016 [citado em 22 de maio de 2017]. Disponível em: https://seer.ufmg.br/index.php/arquivosem odontologia/article/download/1654/1189

25. Figliolia SLC. Fatores de risco para mucosite bucal em pacientes com leucemia linfoide aguda submetidos a diferentes protocolos de tratamento. 2006. [Tese de Doutorado]. Universidade de São Paulo [citado em 22 de maio de 2017]. Disponível em:

http://www.teses.usp.br/teses/disponiveis/2 5/25136/tde-22062007-

141538/publico/SuzanaFigliolia.pdf 
26. Matta JF. Estudo da sobrevida média relativa em portadores de leucemia linfoide aguda. 2011 [citado em 22 de maio de 2017]. [Dissertação de Mestrado]. Disponível em: http://www.teses.usp.br/teses/disponiveis/2 5/25136/tde-22062007141538/publico/SuzanaFigliolia.pdf

27. Souza MS. Estudo epidemiológico dos casos de leucemia linfoide aguda nas crianças e adolescentes tratados no centro de tratamento onco-hematológico infantilCETOHI, do hospital regional de Mato Grosso do Sul. 2013 [citado em 22 de maio de 2017]. [Dissertação de Mestrado]. Disponível em: http://200.129.202.51:8080/jspui/bitstream/ 123456789/1914/1/Souza.pdf

\section{Como citar (Vancouver)}

Cavalcante MS, Santana Rosa IS, Torres F. Leucemia linfoide aguda e seus principais conceitos. Rev Cient Fac Educ e Meio Ambiente [Internet]. 2017;8(2):151-164. DOI: http://dx.doi.org/10.31072/rcf.v8i2.578 